\title{
Punção aspirativa com agulha fina guiada por ultrassom e biópsia por videolaparoscopia em próstata de cães
}

\author{
[Ultrasound guided fine needle aspiration puncture and videolaparocopic biopsy \\ of the prostate of dogs] \\ T.M. Paula ${ }^{1}$, G.H. Toniollo ${ }^{1}$, D.K. Honsho ${ }^{2}$, C.T.N. Duque ${ }^{2}$, V. Páfaro ${ }^{1}$, C. Momo ${ }^{2}$ \\ ${ }^{1}$ Universidade Estadual Paulista -UNESP-Jaboticabal - Jaboticabal, SP \\ ${ }^{2}$ Universidade de Franca - UNIFRAN - Franca, SP
}

\begin{abstract}
RESUMO
Onze cães, sem raça definida, machos, adultos, não castrados e hígidos foram submetidos à punção aspirativa com agulha fina da próstata guiada por ultrassom para avaliação citológica e, após um período mínimo de sete dias, à videolaparoscopia para obtenção de fragmento prostático para avaliação histológica. Nos exames citológicos, dois animais apresentaram alterações celulares compatíveis com hiperplasia prostática benigna. Durante a videolaparoscopia, a colheita do fragmento prostático foi realizada de maneira rápida, não sendo observada hemorragia significativa após o procedimento. Os animais não apresentaram nenhuma complicação no período pós-operatório. Verificaram-se, ao exame histológico, morfologia e estrutura celulares e teciduais nos padrões normais do parênquima prostático em 10 animais; um único cão apresentou alterações celulares e teciduais sugestivas de hiperplasia prostática benigna.
\end{abstract}

Palavras-chave: cão, glândula prostática, ultrassonografia, videolaparoscopia

\begin{abstract}
Eleven healthy intact male mongrel dogs were submitted to prostate ultrasound fine needle aspirative puncture for cytologic exam and, after seven days or more, to videolaparoscopic fragment collection for further histologic evaluation. On cytologic exams, two animals presented changes which correlates with benign prostatic hyperplasia. During the videolaparoscopic proceedings, the prostate fragment collections were made in a quick way and no important hemorrhagic lost has been seen after the collection. The animals presented no complication after the surgeries. The histologic exams showed normal prostate parenchyma based on the cellular and tissue morphology and structure in ten dogs; only one presented cellular and tissue changes suggesting benign prostatic hyperplasia.
\end{abstract}

Keywords: dog, prostatic gland, ultrasonography, videolaparoscopy

\section{INTRODUÇÃO}

A próstata é o único órgão sexual acessório em cães machos, e as afecções prostáticas são relativamente comuns em cães adultos a idosos (Peter et al., 1995). Sua função é produzir fluido como meio de transporte e suporte para os espermatozoides durante a ejaculação. Embora as secreções prostáticas sirvam de veículo para os espermatozoides, não são essenciais para a fertilidade (Krawiec 1994; Vannucchi et al., 1997; Basinger et al., 1998).

As principais afecções prostáticas incluem hiperplasia prostática benigna (HPB), prostatites, abscessos e cistos prostáticos e paraprostáticos, metaplasia escamosa e neoplasias prostáticas (Peter et al., 1995; Johnston et al., 2000; White, 2000).

Recebido em 19 de maio de 2010 
A HPB consiste no aumento do tamanho da próstata como consequência natural do envelhecimento do animal. Está intimamente relacionada ao desequilíbrio hormonal entre andrógenos e estrógenos e ocorre, dessa forma, em cães não castrados (Krawiec, 1994; Peter et al., 1995; Vannucchi et al., 1997). A prostatite bacteriana é uma afecção comum no cão devido à proximidade da próstata com a flora bacteriana normal da uretra, embora uma infecção hematógena seja possível. Pode acometer cães castrados ou intactos sexualmente. O microrganismo mais comumente isolado é a Escherichia coli. Os cistos prostáticos consistem em cavidades não sépticas preenchidas com fluido. A fisiopatologia é incerta, mas pode ocorrer a formação de cistos devido à obstrução dos ductos secretórios da próstata com consequente acúmulo de fluido e formações cavitárias no parênquima ou devido à hiperplasia cística do epitélio glandular (Basinger et al., 1998). As neoplasias prostáticas ocorrem em machos intactos e castrados e, apesar da baixa incidência em cães, o adenocarcinoma é a mais comum das neoplasias em próstata (Peter et al., 1995; Vannucchi et al., 1997; Bostwick et al., 2000; Hedlund 2002). Outras neoplasias também foram descritas, como o carcinoma de células de transição, o carcinoma de células escamosas, o leiomiossarcoma, o linfoma primário fibrossarcoma e as metástases (Vannucchi et al., 1997).

Animais que apresentam sinais clínicos relacionados com disúria, hematúria, polaciúria, tenesmo, constipação, sangramento peniano e desconforto abdominal à palpação devem ter, como diagnóstico diferencial, afecções da próstata (Johnston et al., 2000; White, 2000; Hedlund, 2002). Exames radiográficos, ultrassonográficos, microbiológicos do sêmen, citológicos e histológicos da próstata contribuem para a diferenciação das afecções da glândula. Também as dosagens da fosfatase ácida prostática (PAP) e do antígeno prostático específico (PSA) são importantes para esta diferenciação (Hedlund, 2002; Amorim et al., 2004). A ultrassonografia é um procedimento seguro, não invasivo, que pode ser utilizada não somente para avaliar o tamanho e o contorno da próstata, mas também para avaliar o parênquima glandular e as estruturas com fluido em seu interior (Mattoon e Nyland 1995; Peter et al., 1995; Souza e Toniollo, 1999; Kamolpatana et al., 2000). A citologia aspirativa com agulha fina permite a obtenção de células prostáticas e a consequente avaliação da população celular quanto à morfologia, às características das células e de seus elementos (Powe et al., 2004).

A laparoscopia é um procedimento que permite a visibilização da cavidade abdominal por meio de uma óptica inserida por uma pequena incisão na parede abdominal. Desse modo, é possível a observação de todo o conteúdo da cavidade abdominal, bem como as alterações patológicas, quando presentes (Jones, 1990; Schossler, 1998; Monnet et al., 2003).

Embora o exame citológico auxilie significativamente no diagnóstico, o diagnóstico definitivo para as afecções prostáticas baseia-se no exame histológico de um fragmento da glândula colhido por laparotomia ou laparoscopia ou obtido por meio do exame necroscópico do animal (Peter et al., 1995; White, 2000).

Este trabalho teve por objetivo comparar condições técnicas para a realização da punção aspirativa com agulha fina com auxílio da ultrassonografia da próstata e da colheita de fragmentos prostáticos por meio da videolaparoscopia em cães, quanto à segurança, aplicabilidade, confiabilidade e fidedignidade.

\section{MATERIAL E MÉTODOS}

Foram utilizados 11 cães, adultos, saudáveis, sem raça definida, escolhidos aleatoriamente em um abrigo de cães abandonados. Os cães, com idades entre dois e nove anos, de peso corpóreo variando de 9,1 a 37 quilos, não apresentavam sinais clínicos de doenças prostáticas ou distúrbios reprodutivos. Foram avaliadas as condições clínicas gerais, com ênfase no exame físico e nos índices hematimétricos (eritrograma, leucograma e contagem de plaquetas).

Este estudo foi aprovado pela Comissão Nacional de Ética em Pesquisa da Universidade de Franca, sob protocolo de número 018/09-A.

A próstata foi visibilizada por meio de exame ultrassonográfico (Aparelho Anser 485 - Pie Medical), utilizando-se transdutor convexo de 5,0 e 7,5MHz na região pré-púbica abdominal parapeniana. As dimensões craniocaudal e 
ventrodorsal foram evidenciadas, além da localização, ecogenicidade, presença de nódulos ou formações cavitárias e integridade da cápsula. Foram administrados $0,02 \mathrm{mg} / \mathrm{kg}$ de acepromazina (Acepran 0,2\% - Univet) associada, na mesma seringa, com $0,3 \mathrm{mg} / \mathrm{kg}$ de morfina (Dolo Moff $10 \mathrm{mg} / \mathrm{mL}$ - União química) pela via intramuscular, e procedeu-se à punção, sob visibilização ultrassonográfica com acesso transabdominal, por meio de mandril de cateter calibre 20 (Cateter 20 - Nipro) após ser realizada antissepsia com álcool $70^{\circ} \mathrm{GL}$. A agulha foi introduzida manualmente e acoplada à seringa de $10 \mathrm{~mL}$ para ser aplicada sucção equivalente a 6 $8 \mathrm{~mL}$, por meio de um citoaspirador, no lobo esquerdo da glândula. O material colhido foi colocado sobre lâminas de vidro, estendido e encaminhado para exame citológico. Para coloração das lâminas, utilizou-se o panótico rápido (Laborclin - Produtos para Laboratório Ltda.).

Os cães foram submetidos a jejum alimentar e hídrico por um período de 12 e duas horas, respectivamente. Foram administradas, como medicações pré-anestésicas, atropina (Atropion $0,5 \mathrm{mg} / \mathrm{ml}$ - Ariston) - 0,02mg/kg de peso corpóreo - pela via intramuscular, 15 minutos antes da administração da morfina $-0,3 \mathrm{mg} / \mathrm{kg}$ de peso corpóreo - e xilazina (Sedazine - Fort Dogde) - 0,3mg/kg de peso corpóreo -, associadas na mesma seringa e aplicadas pela via intramuscular. Para a indução anestésica, utilizou-se propofol (Propovan - Cristália) $5 \mathrm{mg} / \mathrm{kg}$ de peso corpóreo -, pela via intravenosa. A manutenção da anestesia foi realizada com halotano (Tanohalo - Cristália), pelo uso de vaporizador calibrado (Modelo 4.2, HB Hospitalar Indústria e Comércio Ltda.) com fluxo diluente de $50 \mathrm{~mL} / \mathrm{kg} / \mathrm{min}$ de oxigênio a $100 \%$, utilizando-se circuito anestésico com reinalação parcial dos gases. Foi instituída a ventilação de pressão positiva intermitente (VPPI), ciclada a pressão $\left(15 \mathrm{cmH}_{2} \mathrm{O}\right)$ com frequência respiratória de 10 a 15 movimentos por minuto. Ao término do procedimento, os animais receberam cetoprofeno (Ketofen 10\% Merial) - $1 \mathrm{mg} / \mathrm{kg}$ - pela via subcutânea, e enrofloxacina (Baytril 10\% - Bayer) - 5mg/kg pela via intramuscular.
Os animais foram posicionados em decúbito dorsal com elevação de $30^{\circ}$ (posição de Trendelenburg) mantendo os membros pélvicos elevados. Após antissepsia com o uso de álcool iodado e solução de iodo povidine a $1 \%$, respectivamente, introduziu-se a agulha de Verres, na região da cicatriz umbilical, que permitiu a instalação do pneumoperitônio artificial com dióxido de carbono, com pressão intra-abdominal instituída variando de 8 a $15 \mathrm{~mm} / \mathrm{Hg}$, na velocidade de $1,2 \mathrm{~L} / \mathrm{min}$, utilizando-se um insuflador automático (Modelo $\mathrm{CO}_{2}-\mathrm{OP}-$ Pneu, Wisap). Após a formação do pneumoperitônio, introduziu-se o trocarte de $10 \mathrm{~mm}$ e óptico, com ângulo de visão de $0^{\circ} \mathrm{e}$ $10 \mathrm{~mm}$ de diâmetro com fonte de luz externa de xenon de 180W (Modelo XE 5600, CD/g - Ilo). Nas regiões abdominais caudais laterais parapenianas esquerda e direita, próximas ao pênis, foram introduzidos os trocartes de $5 \mathrm{~mm}$ de diâmetro para a inserção dos instrumentos cirúrgicos utilizados.

Um fragmento do parênquima prostático foi colhido do lobo direito da glândula, utilizando-se uma pinça de biópsia em forma de colher. Não foi realizado nenhum método para promover hemostasia. O fragmento foi conservado em solução de formalina a $10 \%$ e foram confeccionados cortes histológicos mediante protocolo usual de inclusão em parafina, e corados com hematoxilina e eosina. As três incisões foram aproximadas com a utilização de pontos Sultan com fio náilon 2-0 agulhado para a sutura da musculatura abdominal, e foram utilizados pontos interrompidos simples com o mesmo fio para a sutura da pele. Ato contínuo, realizou-se orquiectomia pré-escrotal, pois os animais foram encaminhados para adoção.

No período pós-operatório, foram administrados o anti-inflamatório não esteroidal cetoprofeno $1 \mathrm{mg} / \mathrm{kg}$ - pela via subcutânea a cada 24 horas, durante três dias, e o antibiótico enrofloxacina $5 \mathrm{mg} / \mathrm{kg}$ - pela via intramuscular a cada 12 horas, durante sete dias. Os animais utilizaram colar elisabetano, e o curativo das feridas cirúrgicas foi realizado com iodo povidine a $1 \%$ a cada 12 horas. 


\section{RESULTADOS}

Verificou-se, por meio do exame ultrassonográfico, que a forma prostática observada foi somente a globosa e a superfície regular em todos os animais. A textura revelouse homogênea em todos os cães, com áreas hiperecoicas circundadas por regiões hipoecoicas.

Foi difícil a visibilização da cápsula prostática em nove animais, mas pôde-se observá-la em dois cães como uma estrutura linear hiperecoica circundando a próstata. Alterações ultrassonográficas compatíveis com hiperplasia prostática benigna foram observadas em três cães. Características como aumento de volume prostático, discreto aumento da ecogenicidade do parênquima e aumento significativo da ecogenicidade da cápsula fibrosa que envolve a glândula foram notadas.

Nos exames citológicos, não foram encontradas alterações inflamatórias, proliferativas ou neoplásicas. Foram observados, em nove animais, muitas hemácias, leucócitos e células epiteliais prostáticas com formato cuboide, citoplasma discretamente basofílico e granular, núcleo grande, redondo a oval, e cromatina com padrão reticular. As células encontradas dispunham-se, de maneira geral, em blocos.

Em dois animais foram observadas células com características sugestivas de hiperplasia prostática benigna, incluindo aumento da relação núcleo:citoplasma, citoplasma mais basofílico contendo algumas vacuolizações, cromatina heterogênea e condensada e blocos celulares maiores.

Após dissecação do tecido adiposo periprostático, durante a biópsia por videolaparoscopia, foi possível observar a próstata, caudalmente à bexiga, com forma globosa, superfície regular, sem alterações na coloração, ausência de nódulos e cistos e sem sinais evidentes da punção realizada há sete dias. Os fragmentos obtidos eram de tamanho aproximado de $0,3 \mathrm{~cm}$ por $0,5 \mathrm{~cm}$ de extensão. Não foi observada hemorragia importante após a remoção do fragmento prostático, e os animais não apresentaram nenhuma complicação póscirúrgica relacionada à recuperação anestésica, cicatrização das feridas cirúrgicas e micção.
Do total de lâminas, 10 apresentaram morfologia e estrutura condizentes com o parênquima prostático normal, incluindo características como única camada celular do ácino e tamanho dele dentro dos limites normais.

Em um dos animais, observaram-se alterações compatíveis com hiperplasia prostática benigna, incluindo dilatação dos ácinos da glândula e aumento do número de camadas de células epiteliais. As alterações celulares epiteliais prostáticas notadas foram o aumento da relação núcleo:citoplasma, cromatina heterogênea $\mathrm{e}$ condensada, ressaltando que, no mesmo animal, não foram percebidas alterações celulares no exame citológico e no exame físico.

\section{DISCUSSÃO}

Os exames ultrassonográficos da próstata foram fundamentais, pois permitiram avaliar características como localização, tamanho, contorno, simetria e parênquima prostático como descrito por Mattoon e Nyland (1995) e Souza e Toniollo (1999). A visibilização da cápsula prostática não foi possível em todos os animais, corroborando com Cartee e Rowles (1983), Feeney et al., (1987), Zohil e Castellano (1994) e Ruel (1997), em razão da presença de fezes nas alças intestinais e do tipo de eco refletido pela cápsula.

Todos apresentaram próstata de forma globosa e superfície regular como descrita por Cartee e Rowles (1983), e apenas dois deles apresentaram aumento de volume prostático. Importante afirmar que o tamanho da glândula sofre influência da idade e raça do animal. Animais idosos tendem a apresentar próstata de maior tamanho devido às alterações hiperplásicas. Neste trabalho, a idade dos animais variou de dois a nove anos, sendo que os dois animais com prostatomegalia apresentavam idade de sete e nove anos, portanto, idosos. Krawiec (1994) e Peter et al. (1995) verificaram aumento de volume prostático, um achado comum em cães, nessas idades, como alteração decorrente da hiperplasia da glândula. O parênquima prostático revelou textura homogênea com áreas hiperecoicas circundadas por pequenas regiões de menor ecogenicidade, semelhantes aos resultados de Feeney et al. (1987) e Mattoon e Nyland (1995). 
Três cães apresentaram alterações ultrassonográficas sugestivas de hiperplasia prostática benigna, incluindo aumento da ecogenicidade do parênquima e aumento de volume da glândula, conforme descreveram Feeney et al. (1987) e Winter et al. (2006). Foi possível a visibilização da cápsula prostática em dois cães, como estrutura linear e hiperecoica circundando a glândula, característica também observada por Cartee e Rowles (1983). A ultrassonografia colaborou significativamente para a realização da punção aspirativa da próstata por permitir, além da avaliação da glândula, a determinação do local da punção, como verificado por Nyland et al. (2002), tornando a colheita do material mais eficaz e segura. Provavelmente, sem o auxílio do exame ultrassonográfico, não seria possível a realização da punção aspirativa da mesma maneira citada.

A punção aspirativa com agulha fina foi possível de ser realizada em todos os animais e permitiu a colheita de material para avaliação das características celulares e de seus elementos, aspectos já verificados por Zohil e Castellano (1994). As características celulares observadas, ao exame citológico, assemelham-se às verificadas por Thrall et al. (1999) no que se refere ao formato da célula e do núcleo, e coloração do citoplasma, isto é, células cuboides com núcleo redondo a oval e citoplasma ligeiramente basofílico. Dois cães apresentaram alterações citológicas compatíveis com hiperplasia prostática benigna, como aumento da relação núcleo:citoplasma, citoplasma mais basofílico e cromatina reticular e condensada, aspectos já discutidos por Thrall et al. (1999).

Um dos animais, que demonstrou alterações ultrassonográficas sugestivas de hiperplasia prostática benigna, não apresentou alterações celulares ao exame citológico condizentes com a enfermidade. Tal observação confirma as já observadas por Powe et al. (2004), que descreveram a possibilidade de colheita de material insuficiente, pela punção aspirativa, para avaliação citológica.

A visibilização dos órgãos abdominais, incluindo a próstata, foi realizada após a introdução da óptica, como descrita por Jones (1990) e Monnet et al. (2003), e a obtenção do fragmento prostático, para avaliação histológica, foi feita de maneira segura, sendo o material suficiente para biópsia, conforme recomendaram Jones (1990) e Richter (2001). Assim como descrito por Monnet et al. (2003), foi observado enfisema subcutâneo em um dos animais, como complicação no momento da instalação do pneumoperitôneo causada pela introdução incorreta da agulha de Verres. O problema foi solucionado pela suspensão da insuflação, massagem para esvaziamento e nova introdução da agulha. Após a correção, foi possível dar continuidade ao procedimento cirúrgico.

A pressão intra-abdominal variou de 8 a $12 \mathrm{~mm} / \mathrm{Hg}$ e permaneceu dentro dos valores considerados seguros, abaixo de $15 \mathrm{~mm} / \mathrm{Hg}$, não causando danos à função respiratória, conforme relataram Jones (1990), Richter (2001), Monnet et al. (2003) e Madeb et al. (2004). Para a instalação do pneumoperitôneo, utilizou-se insuflador automático de dióxido de carbono que, de acordo com Richter (2001) e Monnet et al. (2003), é o gás considerado mais seguro em razão de sua rápida absorção e diminuição do risco de embolia gasosa. Não foi observada nenhuma complicação relacionada ao pneumoperitônio, corroborando com Berger et al. (2005), que relataram a embolia gasosa como uma complicação rara.

A colheita do fragmento prostático, por meio da pinça de biópsia com concha, foi realizada de maneira segura, visto que a videolaparoscopia permite a visibilização direta do local da colheita, na próstata, além do acompanhamento e controle de possível hemorragia após a obtenção do fragmento, como descrito por Jones (1990). Cabe ressaltar que, no presente experimento, essa observação foi sempre verificada; no entanto, em nenhum dos animais foi motivo para interrupção do procedimento cirúrgico.

A recuperação dos animais ocorreu satisfatoriamente, não sendo observada nenhuma complicação relacionada à cicatrização da ferida cirúrgica, micção e estado geral dos cães, confirmando o já observado por Jones (1990), Richter (2001) e Monnet et al. (2003), quando descreveram que a videolaparoscopia é um procedimento minimamente invasivo.

Os exames histológicos forneceram informações sobre a estrutura e a morfologia do parênquima prostático, tornando possível a caracterização morfológica das células e a diferenciação dos 
processos proliferativos de natureza benigna ou maligna como descrito por Amorim et al. (2004). Um dos animais apresentou alterações na estrutura do parênquima da glândula, compatíveis com hiperplasia prostática benigna, como aumento do tamanho dos ácinos glandulares e aumento do número das camadas celulares ao redor de cada ácino. Amorim et al. (2004) descreveram essas características como alterações condizentes com hiperplasia prostática benigna.

Nos cães que apresentaram alterações nos exames citológicos sugestivas de hiperplasia prostática benigna, o exame histológico apresentou-se dentro da normalidade para os padrões do parênquima da glândula. Estas informações são semelhantes às descritas por Peter et al. (1995) e White (2000), em que o diagnóstico definitivo das doenças prostáticas baseia-se na avaliação histológica e na possibilidade de colheita de material insuficiente no momento da punção aspirativa, como descreveu Powe et al. (2004).

Os exames citológicos auxiliam de maneira significativa no diagnóstico das patologias prostáticas, embora exista a possibilidade de colheita de material insuficiente para avaliação, como verificado neste estudo e por Powe et al. (2004). Além disso, a avaliação citológica não fornece informações sobre a morfologia e a estrutura do tecido prostático, que são adquiridas pelos exames histológicos.

\section{CONCLUSÕES}

A videolaparoscopia é um método seguro, minimamente invasivo e viável para visibilização da próstata e do local para obtenção do fragmento. A colheita e o material obtido são suficientes para a avaliação histológica. A recuperação pós-operatória ocorre de maneira satisfatória, e os animais apresentam estado geral bom. O exame citológico permite a avaliação das características celulares e de seus elementos e auxilia no diagnóstico e na diferenciação das doenças prostáticas. $\mathrm{O}$ exame histológico de fragmento prostático, obtido por videolaparoscopia, permite a avaliação da estrutura e da morfologia do parênquima da glândula e fornece o diagnóstico definitivo.

\section{REFERÊNCIAS BIBLIOGRÁFICAS}

AMORIM, R.L.; MOURA, V.M.B.D.; DI SANTIS, G.W. et al. Serum and urinary measurements of prostatic acid phosphatase (PAP) and prostatic specific antigen (PSA) in dogs. Arq. Bras. Med. Vet. Zootec., v.56, p.320324, 2004.

BASINGER, R.R.; ROBINETTE, C.L.; HARDLE, E.M. et al. In. SLATTER, D. Manual de cirurgia de pequenos animais. 2.ed. São Paulo: Manole, 1998. p.1607-1627.

BERGER, T.; SILVA, R.V.; MARUI, A.S. et al. Embolia gasosa por dióxido de carbono durante cirurgia laparoscópica. Relato de caso. Rev. Bras. Anestesiol. v.55, p.87-89, 2005.

BOSTWICK, D.G.; RAMNANI, D.; QIAN, J. Prostatic intraepithelial neoplasia: animal models 2000. Prostate, v.43, p.286-294, 2000.

CARTEE, R.E.; ROWLES, T. Transabdominal sonographic evaluation of the canine prostate. Vet. Radiol., v.24, p.156-164, 1983.

FEENEY, D.D.; JOHNSTON, G.R.; KLAUSNER, J.S. et al. Canine prostatic disease - comparison of ultrasonographic appearance with morphologic and microbiologic findings: 30 cases (1981-1985). J. Am. Med. Assoc., v.190, p.1027-1034, 1987.

HEDLUND, C.S. Cirurgia do sistema reprodutivo e genital. In. FOSSUM, T.W. Cirurgia de pequenos animais. 1.ed. São Paulo: Roca, 2002. p.611-622.

JOHNSTON, S.D.; KAMOLPATANA, K.; ROOT-KUSTRITZ, M.V. et al. Prostatic disorders in the dog. Anim. Reprod. Sci., v.60, p.405-15, 2000.

JONES, B.D. Laparoscopy. Vet. Clin. N. Am.: Small Anim. Pract., v.20, p.1243-1263, 1990.

KAMOLPATANA, K.; JOHNSTON, G.R.; JOHNSTON, S.D. Determination of canine prostatic volume using transabdominal ultrasonography. Vet. Radiol. Ultrasound, v.41, p.73-77, 2000 .

KRAWIEC, D.R. Canine prostate disease. J. Am. Vet. Med. Assoc., v.204, p.1561-1564, 1994. 
MADEB， R.; KONIARIS, L.G.; PATEL, H.R.H.; et al. Complications of laparoscopic urologic surgery. J. Laparoendosc. Adv. Surg. Tech. A, v.14, p.287-301, 2004.

MATTON, J.S.; NYLAND, T.G. Ultrasonography of the genital system. In: NYLAND, T.G.; MATTON, J.S. Veterinary diagnostic ultrasound. Philadelphia: WB Saunders, 1995. p.141-163.

MONNET, E.; TWEDT, D.C. Laparoscopy. Vet. Clin. N. Am.: Small Anim. Pract., v.33, p.11471163, 2003.

NYLAND, T.G.; WALLACK, S.T.; WISNER, E.R. Needle-tract implantation following usguided fine-needle aspiration biopsy of transitional cell carcinoma of the bladder, urethra and prostate. Vet. Radiol. Ultrasound, v.43, p.5053, 2002.

PETER, A.T.; STEINER, J.M.; ADAMS, L.G. Diagnosis and medical management of prostate disease in the dog. Sem. Vet. Med. Surg., v.10, p.35-42, 1995.

POWE, J.R.; CANFIELD, P.J.; MARTIN, P.A. Evaluation of the cytologic diagnosis of canine prostatic disorders. Vet. Clin. Pathol., v.33, p.150-154, 2004.

RICHTER, K.P. Laparoscopy in dogs and cats. Vet. Clin. N. Am.: Small Anim. Pract., v.31, p.707-727, 2001.
RUEL, Y.; BARTHEZ, P.Y.; MAILLES, A. et al. Ultrasonographic evaluation of the prostate in healthy intact dogs. Vet. Radiol. Ultrasound, v.39, p.212-216, 1997.

SCHOSSLER, J.E. Laparoscopia diagnóstica em cães: análise de 27 casos. Braz. J. Vet. Res. Anim. Sci., v.35, p.123-126, 1998.

SOUZA, F.F.; TONIOLLO, G.H. Avaliação da glândula prostática canina. Rev. Bras. Reprod. Anim., v.23, p.243-244, 1999.

THARLL, M.A.; OLSON, P.N.; FREEMYER, F.G. Cytologic diagnosis of canine prostatic disease. J. Am. Anim. Hosp. Assoc., v.12, p.95$102,1999$.

VANNUCCHI, C.I.; VENTURA, P.C.N.; SATZINGER, S. et al. Afecções prostáticas em cães: sinais clínicos, diagnóstico e tratamento. Clin. Vet., v.2, p.37-42, 1997.

WHITE, R.A.S. Prostatic surgery in the dog. Clin. Tech. Small Anim. Pract., v.15, p.46-51, 2000.

WINTER, W.D.; LOCKE, J.E.; PENNINCK, D.G. Imaging diagnosis - urinary obstruction secondary to prostatic lymphoma in a young dog. Vet. Radiol. Ultrasound, v.47, p.597-601, 2006.

ZOHIL, A.M.; CASTELLANO, M.C. Prebubic and transrectal ultrasonography of the canine prostate: a comparative study. Vet. Radiol. Ultrasound, v.36, p.393-396, 1994. 